\title{
EVALUATION OF THE OCCURRENCE OF CANINE CONGENITAL SENSORINEURAL DEAFNESS IN PUPPIES OF PREDISPOSED DOG BREEDS USING THE BRAINSTEM AUDITORY EVOKED RESPONSE
}

\author{
Marta PŁONEK ${ }^{1 *}$, Elżbieta GIZA ${ }^{1}$, Artur NIEDźwIEDŹ ${ }^{1}$, Krzysztof KUBIAK $^{1}$, \\ Józef NICPON $^{1,2}$ and Marcin WRZOSEK ${ }^{1}$ \\ ${ }^{1}$ Department of Internal Diseases with a Clinic of Horses, Dogs and Cats, Faculty \\ of Veterinary Medicine, Wroclaw University of Environmental and Life Sciences, \\ pl. Grunwaldzki 47, 50-366 Wrocław; ${ }^{2}$ Centre for Experimental Diagnostics and \\ Biomedical Innovations, Wrocław, Poland
}

(Received 31 May 2016; accepted 2 November 2016)

Canine congenital sensorineural deafness (CCSD) affects predisposed breeds of dogs and is primarily caused by an atrophy of the stria vascularis of the organ of Corti. The analysis of the brainstem auditory evoked response (BAER) is a reliable method for the evaluation of hearing in animals as it allows an accurate detection of unilateral or bilateral deafness. The occurrence of unilateral and bilateral deafness using the BAER was determined in a representative group of dogs in Poland, including Bull Terriers $(\mathrm{n}=117)$, Australian Cattle Dogs $(\mathrm{n}=62)$, English Setters $(n=32)$ and the Dogo Argentino $(n=32)$. Overall deafness, deafness in each dog breed and an association between deafness and phenotype were studied. Among the 243 dogs tested, 156 (81\%) had a normal BAER, $27(11 \%)$ were unilaterally deaf, and $12(5 \%)$ were bilaterally deaf. The amplitudes and latencies of waves I, II, III, V, the V/I wave amplitude ratio, and wave I-V, I-III and III-V inter-peak intervals were recorded for each dog. Unilaterally and bilaterally deaf dogs were present in all the dog breeds studied. There were $17(14.5 \%)$ deaf Bull Terriers, three (4.8\%) deaf Australian Cattle Dogs, seven (21.9\%) deaf English Setters, and 12 (37.5\%) deaf Dogos Argentinos. Preventive BAER screening should be routinely performed in these four breeds to prevent the spread of genes responsible for deafness.

Key words: Canine congenital sensorineural deafness, dogs, brainstem auditory evoked response, predisposed breeds

Analysis of the brainstem auditory evoked response (BAER) is the most reliable technique for the evaluation of hearing in animals (Wilson and Mills, 2005; Webb, 2009; Wacławska-Matyjasik, 2010). It is carried out by recording the activity of the vestibulocochlear nerve and the auditory part of the brainstem.

\footnotetext{
"Corresponding author; E-mail: marta.plonek@up.wroc.pl; Phone: 0048 (790) 295-549
} 
The BAER is a representation of the electrical impulses that pass from the inner ear through the cochlear nucleus, superior olivary complex, lateral lemniscus and inferior colliculus to the auditory cortex when an acoustic stimulus is applied (Cargill et al., 2004). This minimally invasive method is commonly used to assess hearing in puppies and adult dogs of numerous breeds predisposed to deafness. BAER can be used for diagnosing presbyacusis, differentiating between two types of deafness common in veterinary medicine (sensorineural and conductive deafness) and for localising the site of a lesion within the central nervous system (Knuppel, 2009; Strain, 2011).

Canine congenital sensorineural deafness (CCSD) is the most common cause of canine hearing loss and has been described in 100 breeds of dogs (Strain, 2014). CCSD results from degeneration of the stria vascularis and the hair cells as well as from the collapse of Reissner's membrane and the saccule in the inner ear. It can be pigment associated or neuroepithelial (Strain, 2015). The recessive alleles of the piebald locus $(S)$ and the dominant alleles of the merle locus $(M)$ are suspected of instigating hereditary deafness, although the causative genes and mode of inheritance have not been determined (Strain, 2015). The Bull Terrier (BT) is a breed with homozygous extreme white piebald $\left(\mathrm{s}^{w}\right)$. Hence, white BTs are more likely to be deaf than coloured dogs (Rak and Distl, 2005). Other breeds that carry the recessive piebald alleles include the Australian Cattle Dog (ACD), the Dogo Argentino (DA) and the English Setter (ES). Despite the recognition of an association between phenotype and deafness, the number of contributing genes, their interactions and effects on the phenotypic expression and the mode of inheritance of such mutations have not been identified (Strain, 2004).

To date, a genetic test that allows the detection of deafness in a single dog breed has not been developed. The brainstem auditory evoked response (BAER) allows an accurate diagnosis of unilaterally or bilaterally deaf dogs (Cargill et al., 2004). The results of the BAER and phenotypic data may aid in eliminating deaf individuals from breeding and limit CCSD within a given breed. No data are available on the prevalence of deafness in the Polish population of predisposed dog breeds.

The aim of this study was to determine the prevalence of CCSD in a cohort of four dog breeds presented for a preventive BAER test, and to determine a correlation between the hearing status and the animal's phenotype.

\section{Materials and methods}

The study was carried out on 243 dogs of four breeds predisposed to deafness (Table 1). All the examined dogs were patients of the Department of Internal Diseases with a Clinic of Horses, Dogs and Cats of the Faculty of Veterinary Medicine, Wrocław University of Environmental and Life Sciences. All recordings 
were performed as part of a preventive hearing assessment and did not require the approval of the local Ethics Commitee. All the dogs were purebreds predisposed to deafness and underwent the BAER test as part of a programme to exclude deaf individuals from breeding.

\section{Table 1}

Occurrence of deafness in 243 dogs of predisposed breeds

\begin{tabular}{|c|c|c|c|c|c|c|}
\hline Breed & & $\mathrm{n}$ & $\begin{array}{l}\text { Normal } \\
\text { hearing }\end{array}$ & $\begin{array}{c}\text { Bilaterally } \\
\text { deaf }\end{array}$ & $\begin{array}{c}\text { Unilaterally } \\
\text { deaf }\end{array}$ & $\begin{array}{c}\text { Impaired } \\
\text { hearing } \\
\text { (bilaterally } \\
\text { and unilaterally } \\
\text { deaf combined) }\end{array}$ \\
\hline \multirow{3}{*}{ Bull Terrier } & Total & 117 & $100(85.5 \%)$ & $5(4.2 \%)$ & $12(10.3 \%)$ & $17(14.5 \%)$ \\
\hline & White & 22 & $19(86.4 \%)$ & $1(4.5 \%)$ & $2(9.1 \%)$ & $3(13.6 \%)$ \\
\hline & Coloured & 95 & $81(85.3 \%)$ & $4(4.2 \%)$ & $10(10.5 \%)$ & $14(14.7 \%)$ \\
\hline \multirow{3}{*}{$\begin{array}{l}\text { Australian } \\
\text { Cattle Dog }\end{array}$} & Total & 62 & $59(95.2 \%)$ & $1(1.6 \%)$ & $2(3.2 \%)$ & $3(4.8 \%)$ \\
\hline & Blue & 51 & $49(96 \%)$ & $1(2 \%)$ & $1(2 \%)$ & $2(3.9 \%)$ \\
\hline & Red & 11 & $10(90.9 \%)$ & 0 & $1(9.1 \%)$ & $1(9.1 \%)$ \\
\hline \multirow{3}{*}{$\begin{array}{l}\text { English } \\
\text { Setter }\end{array}$} & Total & 32 & $25(78.1 \%)$ & $2(6.3 \%)$ & $5(15.6 \%)$ & $7(21.9 \%)$ \\
\hline & Blue & 13 & $9(69.2 \%)$ & $1(7.7 \%)$ & $3(23.1 \%)$ & $4(30.8 \%)$ \\
\hline & Red & 13 & $10(76.9 \%)$ & $1(7.7 \%)$ & $2(15.4 \%)$ & $3(23.1 \%)$ \\
\hline \multirow{4}{*}{$\begin{array}{l}\text { Dogo } \\
\text { Argentino }\end{array}$} & Total & 32 & $20(62.5 \%)$ & $4(12.5 \%)$ & $8(25 \%)$ & $12(37.5 \%)$ \\
\hline & White & 29 & $20(69 \%)$ & $4(13.8 \%)$ & $8(27.5 \%)$ & $12(41.4 \%)$ \\
\hline & White with & & & & & \\
\hline & dark patch & 3 & $3(100 \%)$ & 0 & 0 & 0 \\
\hline Total & & 243 & $204(84 \%)$ & $12(4.9 \%)$ & $27(11.1 \%)$ & $39(16 \%)$ \\
\hline
\end{tabular}

Before conducting the BAER, all the tested animals underwent a full clinical and neurological examination, the results of which were unremarkable. After premedication (medetomidine at $20 \mu \mathrm{g} / \mathrm{kg}$, butorphanol at $0.1 \mathrm{mg} / \mathrm{kg} \mathrm{IM}$ ), the animals underwent an otoscopic examination in order to exclude ear canal deformities or other pathologic conditions that could influence the study quality, as well as conductive problems. The tympanic membrane was visualised and was intact in all cases. Any excess debris was removed using cotton-tipped applicators. All the owners were questioned about the dogs' past medical history. Dogs with previous otitis and/or any administration of ototoxic drugs as well as a history of endocrinopathies were excluded from the study.

Auditory brainstem tracings were recorded using a Nicolet Viasys Viking Quest evoked potential system and the Viking Quest software (version 11.0). Four subcutaneous needle electrodes were placed as follows: the reference electrode was placed in the area of the sagittal suture, the ground electrode on the neck above the atlas, and the recording electrode above the mastoid process of 
the tested ear (Fig. 1). The auditory stimulus was emitted through earphones placed inside the external ear canal. In all the patients, the left ear was tested first. The examination was performed using a rarefaction polarity bilateral auditory click stimulus. A $75 \mathrm{~dB}, 90 \mathrm{~dB}$ and $105 \mathrm{~dB}$ nHL intensity was used in the analysed ear. A masking noise of $45 \mathrm{~dB}, 60 \mathrm{~dB}$ and $75 \mathrm{~dB}$ nHL, respectively, was simultaneously applied to the other ear. Each recording was carried out using 300 sweeps and a frequency of $11 \mathrm{~Hz}$ at each intensity. In order to exclude any possible recording artefacts, the impedance of the recording electrodes was maintained below $10 \mathrm{kOhm}$ (ter Haar et al., 2002). Peaks I, II and V were present at $75 \mathrm{~dB}$ in the tracings from dogs that had binaural normal hearing (NH, Fig. 2). Dogs were considered bilaterally deaf (BD) when no tracings were recorded in any of the three sound intensities (Fig. 4). Dogs were deemed unilaterally deaf (UD) when tracings were recorded in only one ear (Fig. 3).

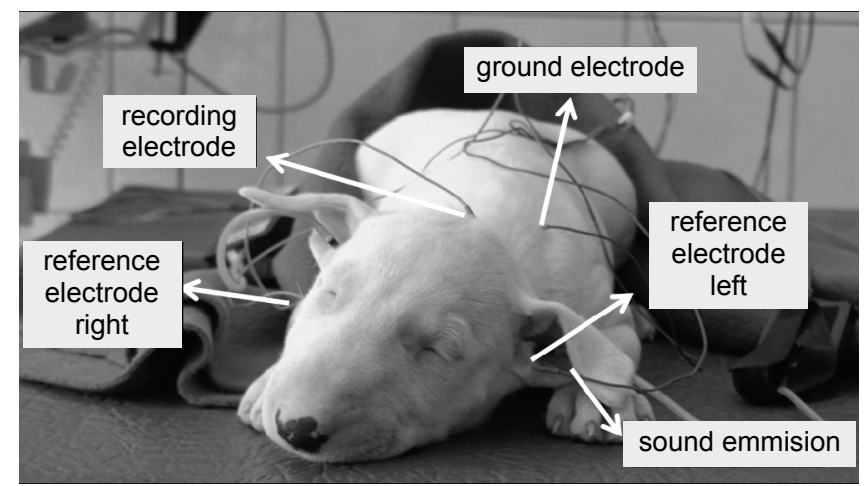

Fig. 1. Electrode placement for BAER testing

The total number of unilaterally and bilaterally deaf dogs was recorded. We also determined the number of unilaterally and bilaterally deaf dogs in each of the four breeds and the association between deafness and gender as well as gender and phenotype in the four breeds of dogs. Our findings were compared with results reported in the literature.

The numbers of healthy, unilaterally and bilaterally deaf dogs in each breed are presented in Tables 1 and 2. The chi-squared test of independence with Yule's Q and Cramer's V contingency coefficient was calculated for the chosen parameters.

\section{Results}

Of the 243 tested dogs, $156(81 \%)$ had normal BAERs, 27 (11\%) were unilaterally deaf and $12(5 \%)$ were bilaterally deaf. The study used tracings obtained from Bull Terriers (BTs) $(\mathrm{n}=117)$, Australian Cattle Dogs (ACDs) $(\mathrm{n}=$ 
62), English Setters $(E S s)(n=32)$ and Dogos Argentinos (DAs $=32)$. The age of the examined dogs ranged from 4 to 184 weeks (mean age: 32 weeks $\pm \mathrm{SD}$; median age: 10 weeks). A total of 130 males and 113 females were tested.

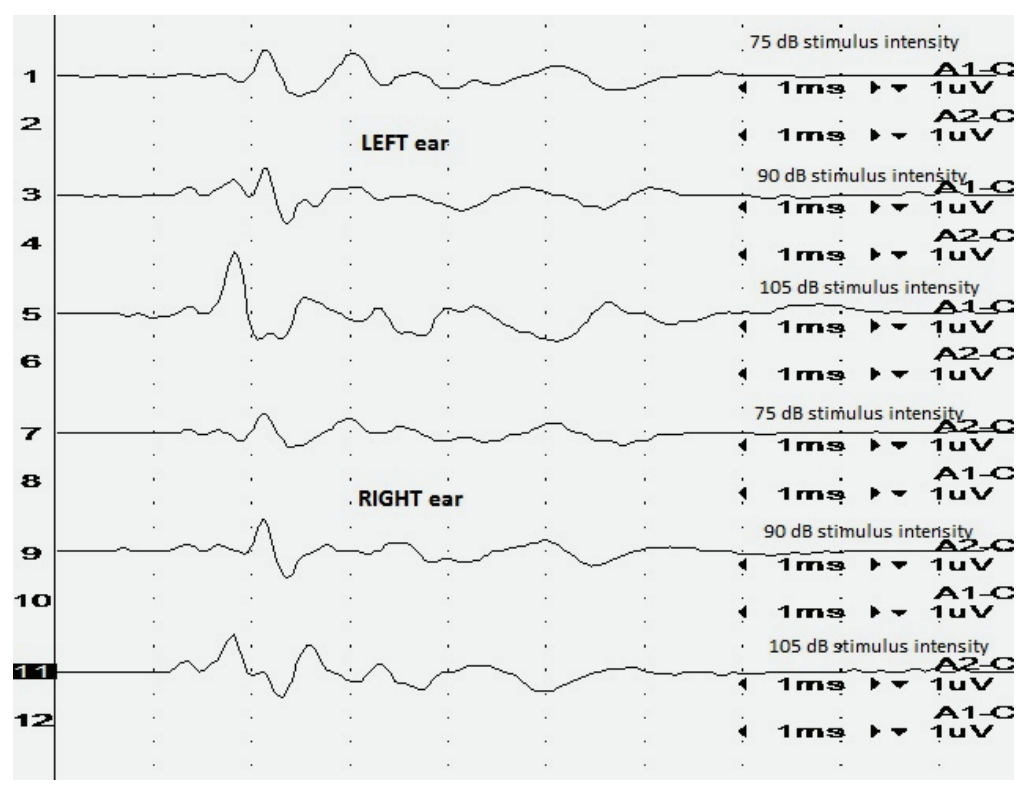

Fig. 2. Normal BAER recording in a dog with bilateral hearing

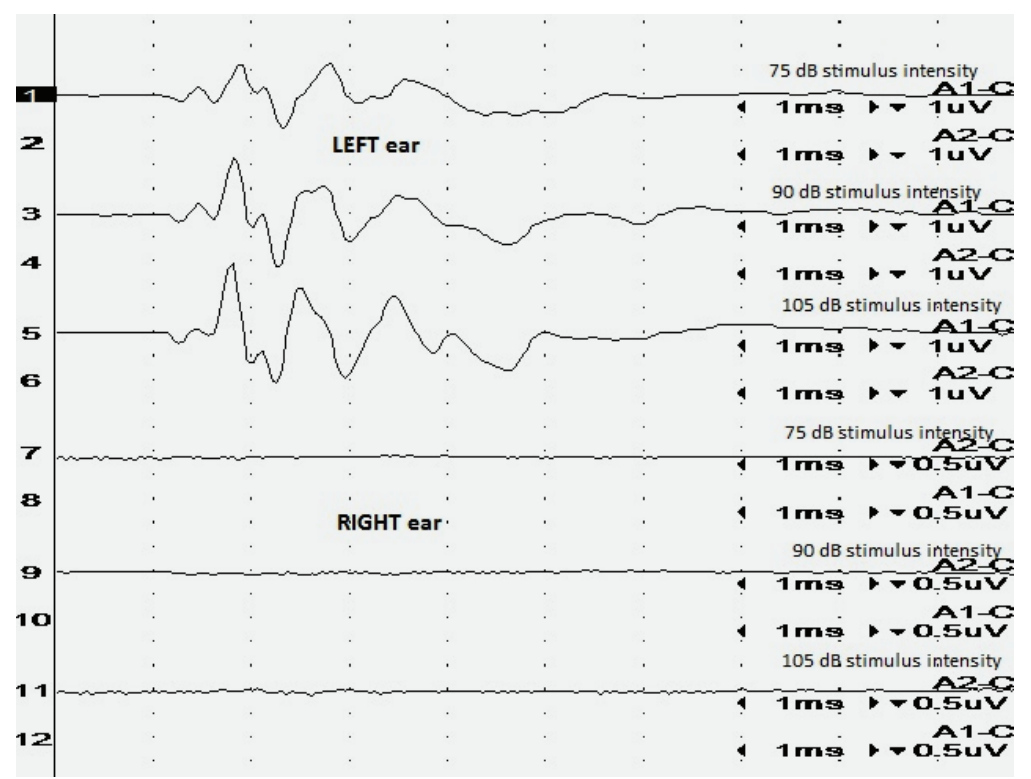

Fig. 3. Recording of right-sided deafness in a dog 


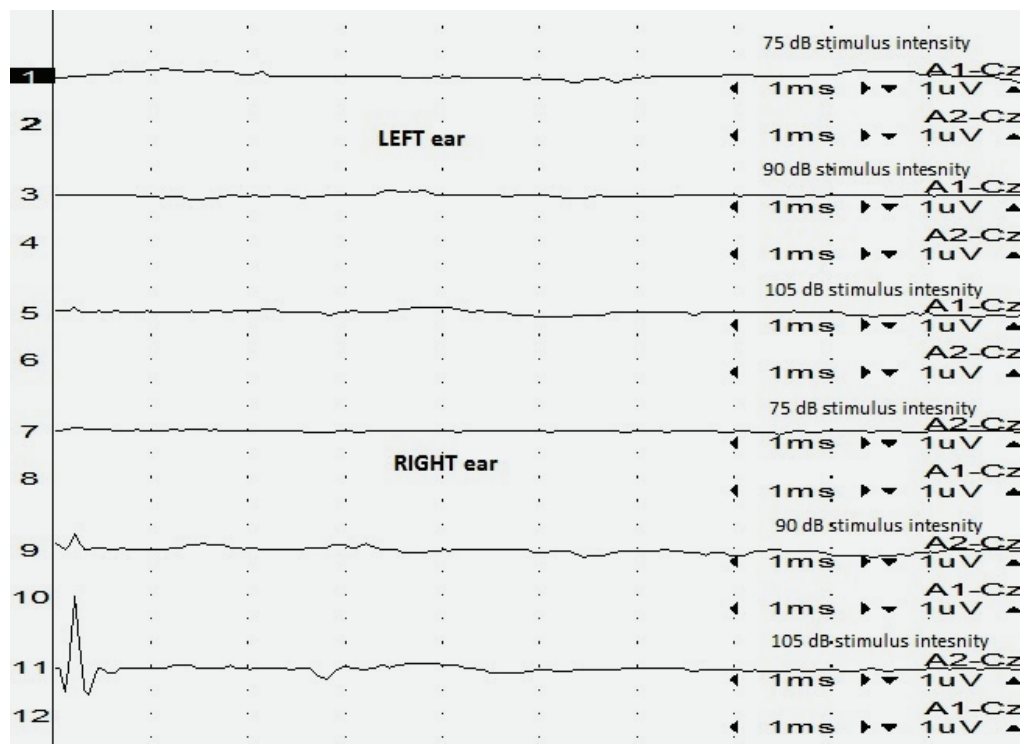

Fig. 4. Bilateral deafness in a dog

Overall, there were equal numbers of bilaterally deaf males $(n=6)$ and females $(n=6)$. There were more unilaterally deaf females $(n=15,56 \%)$ than males $(\mathrm{n}=12,44 \%)$ (Table 2$)$. The percentage of all affected males $(14 \%)$ and females (19\%) was similar.

\section{Table 2}

Gender-related differences in the occurrence of deafness

\begin{tabular}{lccccc}
\hline Gender & $\mathrm{n}$ & $\begin{array}{c}\text { Normal } \\
\text { hearing }\end{array}$ & $\begin{array}{c}\text { Bilaterally } \\
\text { deaf }\end{array}$ & $\begin{array}{c}\text { Unilaterally } \\
\text { deaf }\end{array}$ & $\begin{array}{c}\text { Impaired hearing (bi- } \\
\text { laterally and unilat- } \\
\text { erally deaf com- } \\
\text { bined) }\end{array}$ \\
\hline Male & 131 & $\begin{array}{r}113(86.3 \%) \\
91(81.3 \%)\end{array}$ & $6(4.6 \%)$ & $12(9.2 \%)$ & $18(13.7 \%)$ \\
Female & 112 & $6(5.4 \%)$ & $15(13.4 \%)$ & $21(18.8 \%)$ \\
\hline Total & 243 & $204(84 \%)$ & $12(4.9 \%)$ & $27(11.1 \%)$ & $39(16.0 \%)$ \\
\hline
\end{tabular}

Among the 62 ACDs, there were two unilaterally deaf dogs (3\%) and one bilaterally deaf individual (2\%). In the group of BTs, 12 dogs $(10 \%)$ were unilaterally deaf and five dogs (4\%) were bilaterally deaf. Two ESs $(13.3 \%)$ were binaurally deaf, whereas five (16.7\%) were monaurally deaf (Table 1). Of the 32 studied DAs, eight were unilaterally deaf (22.2\%) and four were bilaterally deaf (11.1\%).

Thirty-eight of the 177 BTs (32\%) were white with markings, $22(19 \%)$ were white, $13(11 \%)$ were red and white, $12(10 \%)$ were brindle with markings, 
six $(5 \%)$ were black brindle, five (4\%) were black tan and white, four were white with an eye-patch $(3 \%)$, three $(3 \%)$ were black brindle and white, three $(3 \%)$ were white and brindle, and two (2\%) were white black and tan. Of the five bilaterally deaf BTs, two were white with brindle (40\%), and there was one each of white, white with marks and black brindle. Of the 12 unilaterally deaf BTs, three $(25 \%)$ were white with an eye-patch, two $(17 \%)$ were white with marks, two $(17 \%)$ were completely white, and there was one dog each with the following coat colours: black brindle, white black and tan, red and white, black and white and tricolour. The percentage results of deafness in white and coloured BTs are presented in Table 1. We did not find an association between the side of deafness and the right-left asymmetry of pigmentation on the head.

Of the 62 ACDs, 47 dogs $(76 \%)$ were blue, six were red (10\%), five were red-speckled $(8 \%)$, two were blue tan $(3 \%)$, and two $(3 \%)$ were blue speckled. One unilaterally deaf ACD was blue while the other was red. The bilaterally deaf ACD was blue.

Thirteen of the 32 ESs were orange-belton (40.6\%), 13 were blue-belton, four were tricolour $(12.5 \%)$ and two dogs were white and orange $(6.3 \%)$. Three unilaterally deaf ESs were blue-belton (23.1\%), and two were orange-belton $(15.4 \%)$. One bilaterally deaf dog was blue-belton $(7.7 \%)$, and the other was orange-belton $(7.7 \%)$.

Twenty-nine (91\%) of the examined DAs were white and three dogs (9\%) were white with markings. All the unilaterally and bilaterally deaf DAs were white.

The chi-squared test of independence with Yule's Q and Cramer's V contingency coefficient revealed no relationship between gender and deafness, the coat colour (white vs. coloured) and deafness in the BT, the ACD (blue vs. red), the ES (blue vs. red vs. tricolour vs. white and orange) and the DA (white vs. white with dark patch) $(\mathrm{P}>0.05)$.

\section{Discussion}

Canine congenital sensorineural deafness (CCSD) is a neurological disease that is particularly common in predisposed dog breeds and has been reported in a variety of other mammalian species, ranging from humans to mice, guinea pigs, and minks. The Dalmatian, the Bull Terrier and the Australian Cattle Dog are the breeds reported to have the highest percentage of congenital deafness (Rak et al., 2003).

CCSD can be identified in dogs as young as four weeks old (Strain et al., 1992). Histological studies have shown that inner ear structures develop physiologically prior to and after birth with atrophy of the stria vascularis occurring between the first and the fourth week of age in affected dogs (Johnsson et al., 1973; Strain et al., 2009). The age of the dogs included in our study ranged from 4 to 184 weeks, at which age the organ of Corti was fully developed. A late-onset inherited congenital sensorineural deafness is a form of congenital deafness which 
occurs later than in the above-mentioned breeds of dogs. It has been reported to occur at the age of 3 months in the Pointer, 5 years in the Border Collie, and from a few weeks old to 3 to 4 years of age in the Cavalier King Charles Spaniel (CKCS) (Podel, 1999; Coppens et al., 2005; DeLahunta et al., 2009; Schmutz, 2014). The probability of late-onset hearing loss was very low in our study since the median age of the studied dogs was 2.5 months. Therefore, a re-evaluation of the unilaterally and bilaterally deaf dogs after several months was not performed.

BAER is a minimally invasive electrodiagnostic test, commonly used to assess brainstem as well as hearing function in animals (Knowles et al., 1988; Poncelet et al., 2000; Wilson and Mills, 2005; ter Haar, 2006; Kang et al., 2008; Knuppel, 2009; Webb, 2009). The diagnosis of hearing abnormalities in companion animals is considered to be challenging, and is based on the animals' behavioural changes, a lower interaction with their owners, and occasional aggression. Bilaterally deaf puppies are regularly identified by experienced breeders through their behaviour, such as quietness, sleepiness and a lower than normal interaction with littermates. At the same time, unilaterally deaf individuals are difficult to identify as most of them are asymptomatic and behave normally. Such animals are of particular risk to breeding, as they spread the deafness gene in the breed population. Therefore, electrodiagnostic evaluation of hearing is necessary to identify these individuals.

The auditory evoked potentials are presented as waves (waves I-V) on a tracing, which corresponds to the activity of cranial nerve VIII and the auditory pathway to the lateral lemniscus (Legatt, 2012) or caudal colliculus (Shiu et al., 1997).

An abnormal BAER recording may be caused by several factors including otitis externa, otitis media, otitis interna (Besalti et al., 2008), ear canal defects, foreign bodies, ototoxic agents, neoplasia or brainstem pathologies (Strain et al., 1992). All patients in this study underwent a clinical and neurological examination to exclude artificial anomalies of the BAER, not related to abnormal hearing. Similarly, it is recommended that an exact otoscopic examination with tympanic membrane visualisation be performed. We did not find any abnormalities in the otoscopic examination.

In this study, $39(16 \%)$ of all tested dogs exhibited unilateral or bilateral hearing loss, which suggests a need for systematic deafness screening in these four breeds of dogs in Poland. In total, there were more unilaterally deaf individuals $(11.1 \%)$ than bilaterally deaf dogs $(4.9 \%)$. This is in accordance with the results of other studies in which the frequency of unilaterally affected animals was generally higher than that of bilaterally deaf animals (Platt et al., 2006).

There are small differences between previous studies and the current one in the occurrence of deafness in the four breeds studied. Strain (2004) showed that $12.2 \%$ and $2.4 \%$ of ACDs exhibited uni- or bilateral deafness, respectively. Sommerlad et al. (2014) recently screened 608 ACD in Australia and found that the prevalence of deafness (either unilateral or bilateral) was $10 \%$. We found that 
$4.8 \%$ of all the studied ACDs were deaf. BTs in this study had an almost four times higher percentage of bilateral deafness (4.2\%) than that reported in previous studies (1.1\%, based on a study of 665 animals) (Strain, 2004). At the same time, unilateral hearing loss in BTs in this study $(10.3 \%)$ was comparable with literature reports $(9.9 \%)$ (Strain, 2004). The percentage of bilateral deafness in the ES in this study was high (6.3\%) compared to $1.4 \%$ recorded in 3656 ESs by Strain (2004). We also noted a higher occurrence of unilateral hearing loss in this breed $(15.6 \%)$ in this study compared to $6.5 \%$ reported by Strain (2004). The differences in the occurrence of deafness in this study and in that of Strain (2004) may be attributed to different study group sizes.

In 2014 , Strain reported $26 \%$ unilaterally deaf and $8.3 \%$ bilaterally deaf DAs (Strain, 2014), which is comparable with the results of our study. The only other literature report concerning deafness prevalence in DAs was that of Coppens et al. (2003), who reported two bilaterally deaf and three unilaterally deaf puppies in a litter of 10 dogs.

We found that there were comparable numbers of white and coloured deaf (either unilaterally or bilaterally deaf) BTs. In contrast, Strain (2004) found significant differences in the prevalence of deafness between white and coloured BTs. He did not note statistically significant differences in the prevalence of deafness between blue, orange and tricolour ESs as well as between blue/blue, tan/blue, black and tan/red ACDs (Strain, 2004). We also found comparable numbers of uni-and bilaterally deaf orange and blue ESs and ACDs.

Associations between deafness and phenotype have been recognised in several breeds. In 2004, Strain analysed a selection of coat colours in the English Setter, English Cocker Spaniel and Australian Cattle Dog and found no association between various coat colours and deafness, as the genes responsible for the variations in coat colour $(B, A, C, D, E)$ are not suspected to be associated with deafness. In the Dalmatian and the Bull Terrier, the presence of head patching is related to a lower incidence of deafness, and is connected to a weaker expression of the $s$ gene. Similarly, breeding away from blue irises has been found to decrease the occurrence of deafness in the Dalmatian (Strain, 2004). The lack of correlation between phenotype and deafness in the four breeds in our study is most likely caused by relatively small population sizes.

The percentage of unilaterally deaf females in this study was slightly higher than that of unilaterally deaf males. However, we did not find a relationship between gender and deafness. Holliday et al. (1992), Greibrokk (1994) and Famula et al. (2001) showed a significant relationship between gender and deafness in the Dalmatian, with a higher prevalence in females, whereas Anderson et al. (1968) found a higher prevalence in males. Strain (2004) reported no gender difference in deafness for the BT, the ACD and the ES. We found that the percentage of deaf dogs in each of the four studied breeds was comparable to that reported in the literature (Coppens et al., 2003; Strain, 2004, 2014). In order to 
determine a correlation between phenotype and deafness as well as between gender and deafness a larger population size is needed.

The present study had some limitations. The dogs involved in it were litters of puppies presented for a routine BAER examination. Hence, the results obtained may not reflect the actual occurrence of deafness among the four breeds of dogs in Poland. In order to carry out an in-depth analysis of deafness prevalence in those breeds, parents and grandparents of the studied animals should also be examined using the BAER technique.

We present the results of BAER screening performed in a population of four breeds of dogs predisposed to canine congenital sensorineural deafness in Poland. In the authors' opinion, preventive electrodiagnostic auditory tests should be carried out routinely in the Polish population of Bull Terriers, Australian Cattle Dogs, English Setters and Dogos Argentinos. This is the only objective method of diagnosing animal deafness and is likely to reduce the spread of genes responsible for deafness within a given breed population. Although BAER is not mandatory for these breeds as per the Polish Kennel Club regulations, more should be done to monitor deafness in the Polish population of dogs predisposed to deafness.

\section{References}

Anderson, H., Henricson, B., Lundquist, P. G., Wedenberg, E. and Wersall, J. (1968): Genetic hearing impairment in the Dalmatian dog. An audiometric, genetic and morphologic study in 53 dogs. Acta Otolaryngol. Suppl. 232, 231-234.

Besalti, O., Sirin, Y. and Pekcan, Z. (2008): The effect of chronic otitis externa-media on brainstem auditory evoked potentials in dogs. Acta Vet. Brno 77, 615-624.

Cargill, E. J., Famula, T. R., Strain, G. M. and Murphy, K. E. (2004): Heritability and segregation analysis of deafness in U.S. Dalmatians. Genetics 166, 1385-1393.

Coppens, A. G., Gilbert-Gregory, S., Steinberg, S. A., Heizmann, C. and Poncelet, L. (2005): Inner ear histopathology in 'nervous Pointer dogs' with severe hearing loss. Hear Res, 200, 5162. doi: 10.1016/j.heares.2004.08.019

Coppens, A. G., Steinberg, S. A. and Poncelet, L. (2003): Inner ear morphology in a bilaterally deaf Dogo Argentino pup. J. Comp. Pathol. 128, 67-70.

DeLahunta, A., Glass, E. and Kent, M. (2009): Veterinary Neuroanatomy and Clinical Neurology. Third edition. Saunders, Philadelphia.

Famula, T. R., Oberbauer, A. M. and Williams, D. C. (2001): Gender effects in hearing loss in Dalmatians. Prev. Vet. Med. 48, 15-24.

Greibrokk, T. (1994): Hereditary deafness in the Dalmatian: relationship to eye and coat color. J. Am. Anim. Hosp. Assoc. 30, 170-176.

Holliday, T. A., Nelson, H. J., Williams, D. C. and Willits, N. (1992): Unilateral and bilateral brainstem auditory-evoked response abnormalities in 900 Dalmatian dogs. J. Vet. Intern. Med. 6, 166-174.

Johnsson, L. G., Hawkins, J., Muraski, A. and Preston, R. (1973): Vascular anatomy and pathology of the cochlea in Dalmatian dogs. In: de Lorenzo, A. J. D. (ed.) Vascular Disorders and Hearing Defects. University Park Press, Baltimore. pp. 249-295.

Kang, B. T., Jung, D. I. and Woo, E. J. (2008): Bilateral congenital deafness in a white Bull Terrier: brainstem auditory evoked response findings. J. Vet. Clin. 25, 506-509. 
Knowles, K. E., Cash, W. C. and Blauch, B. S. (1988): Auditory-evoked responses of dogs with different hearing abilities. Can. J. Vet. Res. 52, 394-397.

Knuppel, J. M. (2009): Correlation of neurologic status as evaluated by neurologic examination and brainstem auditory evoked response test with computed tomographic and radiographic morphometric analysis of the caudal skull in Cavalier King Charles Spaniels. The Ohio State University. Retrieved from http://rave.ohiolink.edu/etdc/view?acc_num=osu1243866074

Legatt, A. D. (2012): Brainstem auditory evoked potentials: methodology, interpretation and clinical application. In: Aminoff, M. J. (ed.) Electrodiagnosis in Clinical Neurology. Sixth edition. Elsevier Saunders, Philadelphia.

Platt, S., Freeman, J., Stefani, A., Wieczorek, L. and Henley, W. (2006): Prevalence of unilateral and bilateral deafness in border collies and association with phenotype. J. Vet. Intern. Med. 20, 1355-1362.

Podel, M. (1999): Advances in assessing canine degenerative hearing loss. Proceedings, American College of Veterinary Internal Medicine Congress.

Poncelet, L., Coppens, A. and Deltenre, P. (2000): Brainstem auditory evoked potential wave V latency-intensity function in normal Dalmatian and Beagle puppies. J. Vet. Intern. Med. 14, 424-428.

Rak, S. G. and Distl, O. (2005): Congenital sensorineural deafness in dogs: A molecular genetic approach toward unravelling the responsible genes. Vet. J. 169, 188-196.

Rak, S. G., Drögemüller, C., Leeb, T., Quignon, P., Andre, C., Scott, A. and Distl, O. (2003): Chromosomal assignment of 20 candidate genes for canine congenital sensorineural deafness by FISH and RH mapping. Cytogenet. Genome Res. 101, 130-135.

Schmutz, S. (2014): An analysis of the inheritance pattern of an adult-onset hearing loss in Border Collie dogs. Canine Genet. Epidemiol. 1, 6. doi: 10.1186/2052-6687-1-6

Shiu, J., Munro, K. and Cox, C. (1997): Normative auditory brainstem response data for hearing threshold and neuro-otological diagnosis in the dog. J. Small Anim. Pract. 38, 103-107.

Sommerlad, S. F., Morton, J. M., Johnstone, I., O'Leary, C. A. and Seddon, J. M. (2014): Consequences of a screening programme on the prevalence of congenital hereditary sensorineural deafness in the Australian Cattle Dog. Anim. Genet. 45, 855-862.

Strain, G. M. (2004): Deafness prevalence and pigmentation and gender associations in dog breeds at risk. Vet. J. 167, 23-32.

Strain, G. M. (2011): Deafness in Dogs and Cats. First edition. CABI, Wallingford, UK and Cambridge, MA, USA.

Strain, G. M. (2014): Dog breeds with reported congenital deafness. Retrieved 25.05.2016, from http://www.lsu.edu/deafness/breeds.htm

Strain, G. M. (2015): The genetics of deafness in domestic animals. Front. Vet. Sci. 2, 29.

Strain, G. M., Clark, L., Wahl, J., Turner, A. and Murphy, K. (2009): Prevalence of deafness in dogs heterozygous or homozygous for the merle allele. J. Vet. Intern. Med. 23, 282-286.

Strain, G. M., Kearney, M. T., Gignac, I. J., Levesque, D. C., Nelson, H. J., Tedford, B. L. and Remsen, L. G. (1992): Brainstem auditory-evoked potential assessment of congenital deafness in Dalmatians: Associations with phenotypic markers. J. Vet. Intern. Med. 6, 175-182.

ter Haar, G. (2006): Inner ear dysfunction related to ear disease in dogs and cats. Eur. J. Comp. Anim. Pract. 16, 127-135.

ter Haar, G., Haagen, A., Groot, H. and Brom, W. (2002): Click and low-, middle-, and highfrequency toneburst stimulation of the canine cochlea. J. Vet. Intern. Med. 16, 274-280.

Wacławska-Matyjasik, A. (2010): Application of brainstem auditory evoked potentials in the diagnosis of hearing disorders in dogs [in Polish]. Medycyna Weterynaryjna 66, 246-250.

Webb, A. A. (2009): Brainstem auditory evoked response (BAER) testing in animals. Can. Vet. J. 50, 313-318.

Wilson, W. J. and Mills, P. C. (2005): Brainstem auditory-evoked response in dogs. Am. J. Vet. Res. 66, 2177-2187. 